\title{
Application of Simulation Modelling Means in Management Decisions-making within the Security and Defence Sector
}

\author{
Artem Bratko ${ }^{1 *}$, Viktor Bereziuk ${ }^{2}$, Artem Shevchenko ${ }^{3}$, Yaroslav Kubetsky ${ }^{4}$, \\ Valentyn Didyk ${ }^{5}$, Serhii Serkhovets ${ }^{6}$ \\ ${ }^{1}$ Associate Professor of the General Military Disciplines Department, Bohdan Khmelnytskyi National Academy of the State Border \\ Guard Service of Ukraine, Khmelnytskyi 29007, Ukraine \\ ${ }^{2}$ Associate Professor of the Border Control Department, Bohdan Khmelnytskyi National Academy of the State Border Guard Service of \\ Ukraine, Khmelnytskyi 29007, Ukraine \\ ${ }^{3}$ Deputy Chief of Logistics, Main Training Center named after Major General Ihor Momot, Cherkasy 18000, Ukraine \\ ${ }^{4}$ Deputy Chief of the Department, Bohdan Khmelnytskyi National Academy of the State Border Guard Service of Ukraine, Khmelnytskyi \\ 29007, Ukraine \\ ${ }^{5}$ Post Graduate Student of the Scientific and Organizational Department, Odesa Military Academy, Odesa 65000, Ukraine \\ ${ }^{6}$ Associate Professor of the Department, Bohdan Khmelnytskyi National Academy of the State Border Guard Service of Ukraine, \\ Khmelnytskyi 29007, Ukraine
}

\section{Abstract}

Problems and modern tendencies in the field of creating complex models of combat operations are considered. The systematic analysis of existing models of combat operations is carried out and their conformity to modern conditions and development of military art is defined. Features of combat operations models development when using means of simulation modelling are exposed with the use of a method of mathematical simulation. The structure of the complex simulation modelling of actions of forces is formed. The composition of standard models of components of the security and defence sector is determined and the sphere of their application is outlined, which allows controlling the unit in different situations at the stage of choosing decisions at different levels of management. The main directions of the development of modelling complexes and systems are determined. The practical implementation of these approaches, along with the implementation of the principles of cost-effectiveness of models, their coordinated development, system compatibility of models for different purposes and large-scale use of proven commercial decisions will create a cluster of combat operations models, which is a real tool for effective decision-making on troops management and allows laying down technical requirements for the development of a modern complex of simulation modelling.
Keywords:

Simulation Modelling;

Operational and Service Activities;

Decision-making;

Security and Defence.

Article History:

$\begin{array}{llll}\text { Received: } & 12 & \text { April } & 2021 \\ \text { Revised: } & 17 & \text { June } & 2021 \\ \text { Accepted: } & 02 & \text { July } & 2021 \\ \text { Published: } & 01 & \text { August } & 2021\end{array}$

\section{1- Introduction}

The stages of calculating management parameters and forecasting the consequences of decisions are the main components of the decision-making process. This applies to any process i.e. planning operations, command of troops (forces) and weapons, arms development. Design missions and mathematical models from the special software of automated troop (forces) command and control system are used in the practice of command and control organizations in order to perform calculations and obtain forecasts.

*CONTACT: bratkoav84@gmail.com

DOI: http://dx.doi.org/10.28991/esj-2021-01294

(C) 2021 by the authors. Licensee ESJ, Italy. This is an open access article under the terms and conditions of the Creative Commons Attribution (CC-BY) license (https://creativecommons.org/licenses/by/4.0/). 
Modelling is a method of problems solving where the system under study is replaced by a simpler object that describes the real system and is called a model. Modelling is used in cases when it is impossible or impractical to conduct experiments on the real system, for example, due to the fragility or high cost of prototyping or due to the duration of the experiment in real time [1]. The model in the armed forces of the world's leading countries is defined as an abstraction that represents a system or system behaviour within certain constraints. Modelling is a system that is described by the model in order to study, analyse or predict its functioning [1]. It is important to point out in this context that both the models themselves and the modelling process will be objects and events of the virtual world close to reality, although the level of their detail can vary significantly.

For example, individual samples of armaments and military equipment, their structural elements (weapons, sensors, etc.), motion physics, and ballistic characteristics of individual munitions can be modelled. On the other hand, it is possible to model hundreds of units of equipment and weapons with sufficient accuracy, which are represented by a single operational and tactical symbol (sign), and their combat capabilities can be described by one variable; landscape of the area, covering hundreds and thousands of kilometers and the ratio of forces of the warring parties. In both cases, the accuracy of the system is less important than the sequence of interaction between objects within it. The sequence of interaction allows the user to adjust his perception of the real world and enter it at the appropriate level.

The models differ significantly, but essentially describe the most important features of the real world and transfer them into a virtual world. In all cases, this process is successful if the developers follow some basic principles. It cannot be as curtained that each principle is a set of useful recommendations that can serve as invaluable recommendations for the development of modelling in general, as well as for the creation of models, games and virtual worlds [2]. Today, simulation modelling is used in order to qualitatively train future commanders, as well as to predict the course of combat operations conduct and its analysis. The simulation modelling provides an opportunity to accomplish the task effectively with lower expenses of material and financial resources, as well as the absence of losses on the part of servicemen and civilians. The commander can clearly solve a task in an artificial combat operation or tactical situation.

\section{2- Literature Review}

Recently, publications touching upon the topic of armed confrontation modelling have begun to appear more and more often in many scientific journals. Their analysis shows that the opinions of different authors currently are quite contradictory and differ significantly from each other, ranging from complete rejection of modelling as such to a completely objective understanding of the need for its implementation.

Thus, Kazmirchuk et al. (2009), and Bakhvalov \& Hirkh-Yalan (2014) provided review of the basic principles and foundations of application of simulation modelling, as well as the history of creation, implementation and latest trends in the development of simulation modelling for the training of armed forces troops of the world's leading countries. The experience of introduction and further prospects of development of simulation modeling means of armament, military equipment and application of military formations of all levels in the general system of combat training of the Armed Forces of Ukraine are analysed [3, 4].

Sorokin et al. (1995), Dewar et al. (1996) and Bobylov \& Timoshenko (2019) considered one of the possible methodological approaches to the construction of simulation modeling means of tactical level combat operations for tactical units of the ground forces. The concept of a typical object for the conduct of combat is introduced, i.e. a combat unit that is not subject to division into smaller components and is able to independently perform the following tasks during combat operations: executing manoeuvre; conducting enemy reconnaissance; carrying firepower against the enemy, as well as making decisions to perform the above tasks. Such simulation modelling means can form the basis of simulation modelling means at higher levels of management, which focus on the decision-making process. The approach to the analysis and data processing on the basis of which decisions on a typical combat object (unit) management are made is offered [5-7].

Derhiliova et al. (2016), Shynkaruk \& Mykhailyshyn (2020), and Permiakov (2006) considered the method of preparation and conduct of command-and-staff training exercise, including multinational, with the help of computers using simulation-modelling resources. The cycle of works on creation of means and systems of the distributed simulation modelling on a platform of modern computers and operating systems is described. As we can see, the coverage of aspects of the application of simulation modelling in the military sphere is ongoing. The training of the representatives of the joint staff, other military formations and law enforcement agencies, as well as allied states is taken into account [8-10]. Zaika et al. (2020), and Kononenko \& Zaika (2013) on the basis of determining the peculiarities of using the method of management decision simulation, JCATS simulation modelling system consider the methodological basis for the implementation of the method of computer management decision simulation with the use of simulation modelling means of combat operations during practical classes (training) with military specialists. The experience of using video games as an effective tool of the simulation modelling system of combat operations is considered. The advantages and disadvantages of adapting commercial software for military purposes are described $[11,12]$. 
Some people without discerning the essence of the mathematical subtleties of models construction, consider it sufficient to use a mathematical apparatus for comparing combat potentials in justifying the decisions, others, hoping for the ability of commanders to logically build a mental model of future combat, generally refuse to use models, but still others, understanding the point give assumptions and limitations, consider the apparatus of mathematical modelling to be a reliable tool for management decisions-making [13, 14].

\section{3- Materials and Methods}

Up till now, we have witnessed a radical transformation, which has taken place both in the content of the armed confrontation and in the forms and methods of operational and combat use of troops. There was a transition from classical forms of warfare to new, undeclared methods of warfare (political, diplomatic, economic, informational, etc.).The possibility of using existing models as a tool to support the decision-making in military management has been virtually ruled out along with new trends in the development of the art of war.

Currently, the practice of military management is a clearly characterised with the contradiction between the need for headquarters in a multifaceted approach to the forecast and the outcome of armed conflict and the abilities of existing models to adequately ensure it. The presence of this contradiction creates an extremely important military-scientific applied task, which is a detailed scientific study of the main areas of contradictions resolution and scientific substantiation of ways to create new and modern complexes and modelling systems that will enable a qualitatively new level of management decisions-making. Figure 1 below shows the procedure for processing the paper.

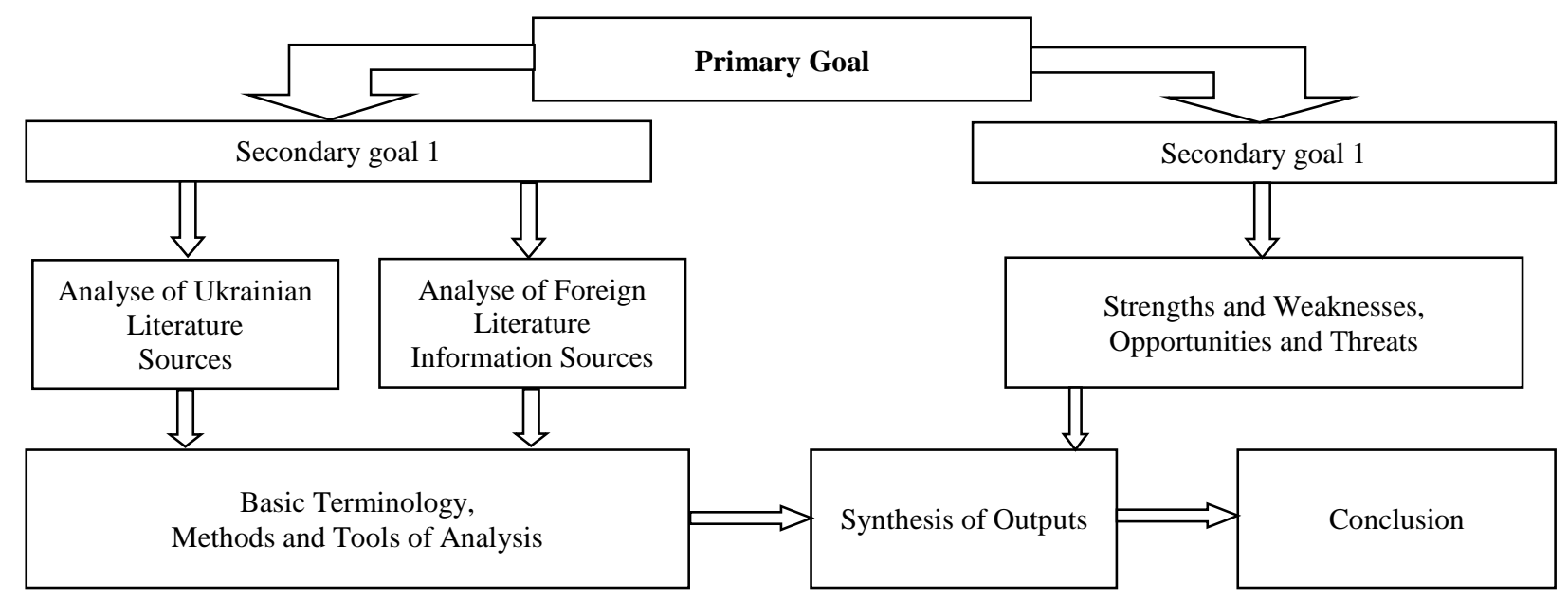

Figure 1. Flowchart of the research methodology.

\section{4- Results of Discussion}

First of all, when designing models, developing system and software solutions, we proceed from the aim of modelling, its functional purpose and the place of models within the system of support for management decisionsmaking. Of course, the model itself will not be able to ensure the development of the only correct and well-founded management decision in specific conditions under a given situation, but is only a tool to support the mental and creative activities of the commanders (chiefs) and headquarters officials. In addition, this is quite justified. It is well known that the planning of any operation or battle is the embodiment of the military art of the commanders (chiefs), who are able to make the right decision based on their own experience and in tuition according to the situation. The model in this case is an auxiliary tool to support this process and assess possible alternatives. This is due to the fact that the mathematical apparatus and algorithms implemented in it cover many complex processes, factors and conditions that directly affect the modelling results. Some of them are set quantitatively, such as field strength and troop population, types and characteristics of weapons and military equipment, logistics and technical support, physical-geographical and meteorological conditions, etc. The rest of the source data cannot be quantified and taken into account in the model for objective reasons, because they touch upon the cognitive sphere of a human being and his morale and martial spirit. Therefore, only formal features are taken into account today in the process of combat operations modelling.

The second no less important methodological feature is the obligatory consideration of the bilateral nature of armed confrontation, namely the processes of confrontation of two antagonistic systems, which enter into not only combat but also intellectual confrontation realizing their concept of the operations [15].Within this framework, the operation or battle today is considered not only as an armed confrontation of two antagonistic systems, but also as systems that simultaneously realize all their combat, information, psychological and logistical potential, which is taken into account in the two decisions of the warring parties. That is, the intellectual confrontation of two opponents, who implement their decisions through the prism of the actions of their troops. In structural terms, this approach provides an 
opportunity to create a bipolar model, which consists of two competing command and control centres, represented by private models, at several levels of management (Figure 2) [16].

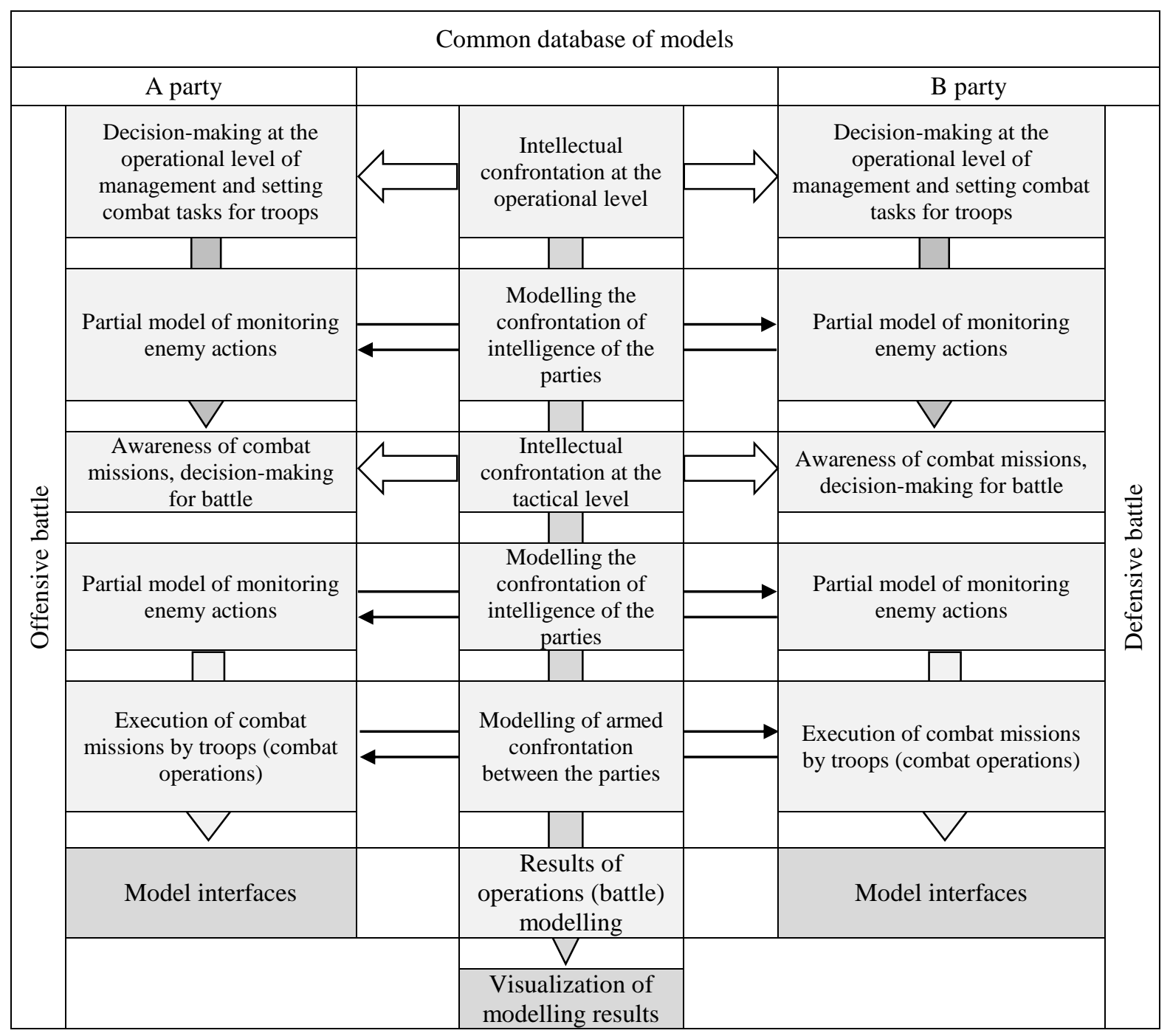

Figure 2. The structure of combat operations model, taking into account the intellectual confrontation of the parties.

As we can see, it is not the material component of the war that comes to the fore, but the products of the commanders' consciousness and will, namely, the decision made and the tasks set for the troops.In implementing this approach, it should be borne in mind that, despite the fact that the given structure adheres to the symmetry of the parties, the results of conduct of operations must be considered through the prism of achieving goals and accomplishment of combat missions namely by friendly troops. The enemy in this case is seen as an external source of unpredictable and sometimes unfavourable actions that force us to seek new, in accordance with the development of the situation, decision.

The conduct of combat operations are modelled at three management levels within the given structure. The first level provides modelling in the interests of decision-making by commanders and setting combat missions at the operational and tactical level. The second covers the processes of making management decisions and setting combat tasks in the tactical chain of command. And the third level is a level of performers accomplishing the set combat tasks, that is directly servicemen of tactical formations. It simulates the practical implementation of decisions made at two higher levels. In essence, the third level is a set of private models of the conduct of combat operations of different types and branches of troops and is a "physical" environment of the model, which simulates not just an armed confrontation, but a set of confrontations in all spheres of their manifestation.

The main difficulty in implementing this approach is the need to change the outdated paradigm of creative thinking and ensure understanding that today the mental activity of commanders at all levels and their decisions must be considered as a product of their consciousness and a major factor in success. The third feature of model development is to ensure human participation in the modelling process through dialogic "human-machine" procedures. Here we proceed from the fact that the performance of operational and tactical calculations should be made by specific official functionaries who monitor the intermediate results and should assess the possible options for influencing the 
development of changes in the combat situation. Due to this, the operator has the opportunity not only to enter new data, obtain intermediate and final quantitative indicators, but also to change the modelling conditions, clarify and assess the impact of various factors upon the previously developed operation plan. To this end, the modelling process is programmed discretely, in stages and with step-by-step fixation of the state and position of the forces and means of the parties. Each stage provides for the possibility to enter new data and obtain different options of management decisions.

It is necessary to understand in the process of this approach implementation that no matter how good the model is and no matter how great its capabilities are, the effectiveness of its application will be determined by its usability, namely the ease of setting base data, clarity and obviousness of the results obtained. This provides, due to the timely receipt of reliable and up-to-date information, a deep understanding of the situation and as a consequence making management decisions by the commander in accordance with the environment on the basis of common sense, his logic and intuition.The fourth feature of model development is the primary implementation of the principle of consistent progress in stages and directions of model construction. This principle makes it possible to systematically provide the most rational and holistic order of model development. To do this, the construction process is divided into a number of separate stages, which allow using the holistic principle to correct each of them with the possibility of minor adjustments to the previous stages. A variant of this sequence of model construction is presented in the form of a graph (Figure 3) [16]. As you can see, the construction and development of the model includes a number of stages and substages.

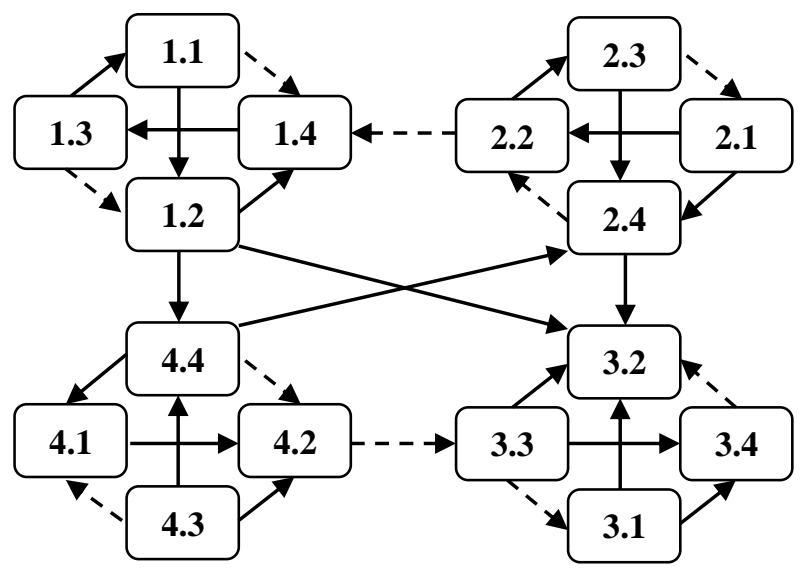

Figure 3. The relationship between the structural components of the model construction.

Name of stages and sub stages:

1. Development of a system of requirements for the model construction, arising from its intended purpose:

1.1. Operational requirements (practice of martial arts).

1.2. Requirements arising from the general tasks of modelling.

1.3. Requirements due to the basic properties of the modelling object.

1.4. Requirements due to the need to model the characteristics that determine the properties of the modelled object.

2. Schematization of the modelled object:

2.1. Schematization of the object composition.

2.2. Schematization of the object structure.

2.3. Schematization of the object organization.

2.4. Schematization of the object operability.

3. Development of the model conceptual form:

3.1. Determining the model composition.

3.2. Development of the model structure.

3.3. Organization of the model operability.

3.4. Requirements for the model design.

4. Development of the model constructive design:

4.1. Choice of mathematical apparatus.

4.2. Constructive description of the elements and connections of the object.

4.3. Identification of parameters.

4.4. Modification, acceptance and application of the model. 
The connection of the tasks solved at each stage or sub-stages is represented by oriented lines of the graph, where solid lines reflect the main sequence of development, and dotted ones show complementary refinements. The construction cycle begins with the definition of the initial requirements for the model and ends with the verification of its compliance with the requirements of the practice of martial arts. The process of the model development is an iterative process of successive approximations, and the graph reflects a fairly clear order of justification of its structure and content.

In general, this approach allows you to clearly define the structure and sequence of construction of the model, choose the appropriate mathematical apparatus and ensure taking the most adequate management decisions in accordance with the complicated conditions. The next feature is in the development of the methodology of the mathematical apparatus of modelling and its adaptation to modern conditions of armed confrontation. We will stop on the general approaches which are accepted in the development process of models of conducting military operations within the limits of our article and without going into features and subtleties of the mathematical description and algorithm presentation.

Let us imagine a battle (operation) in the form of some $Q$ object having $C_{1}, \ldots C_{m}$, properties (internal properties of the object). To obtain a model that describes these properties, you must:

1. Determine the indicators that quantitatively describe the properties of $\bar{Y}^{*}=\left(Y_{1}, \ldots Y_{k}\right)$ object.

2. Describe the properties of the external environment in the selected format as external $X_{1}, \ldots X_{n}$, factors which affect certain indicators of the internal properties of the object through $Z_{1}, \ldots Z_{r}$ parameters. In this case, it is advisable to include the properties of the object that were not taken into account in the group of unaccounted $W_{1}, \ldots W_{s}$ factors.

3. Determine the relationship of the indicators, factors, properties, parameters and make a mathematical description of the object in accordance with the general order of its operability in the model. The diagram of this description in a generalized form is presented in Figure 4 [16].

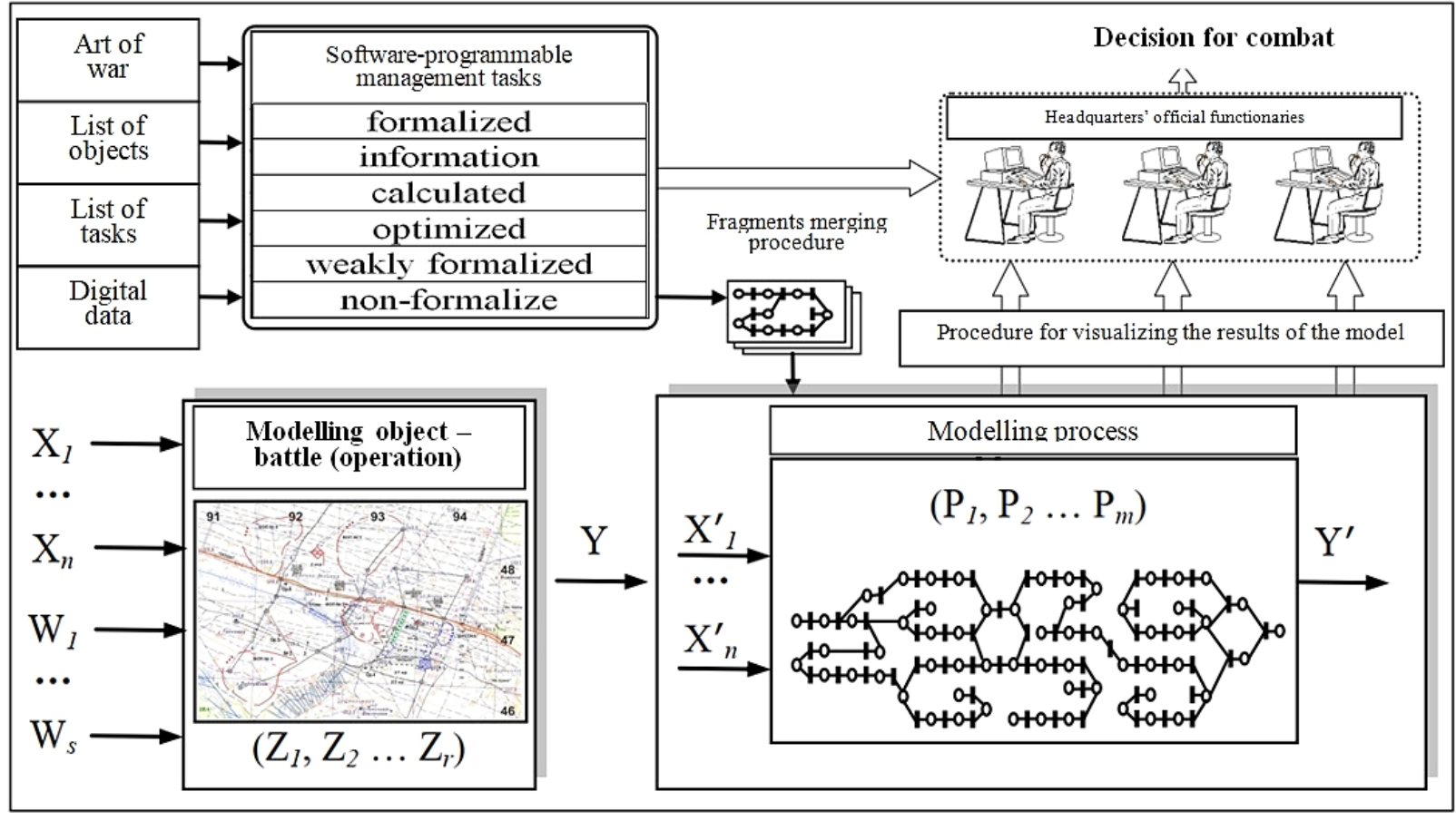

Figure 4. Block schematic diagram of the description of the model of combat operations.

As we can see, the object of modelling is characterized by a functional relationship between the indicators of its properties and parameters:

$\overline{\mathrm{Y}}=f\left(X_{1}, \ldots X_{n}, Z_{1}, \ldots Z_{r}, W_{1}, \ldots W_{s}\right)$

As a rule, only those factors and conditions that most significantly affect the real object of modelling are taken into account in this functional connection. However, these factors and conditions can almost always contain errors given the high degree of uncertainty of the combat situation. As a result, the model of combat operations is an approximate description of actual combat operations and, as a rule, differs from them in its internal parameters. The model is determined by the adequacy of the response of $Y_{1}, \ldots Y_{k}$ indicators of the model and the object of modelling to changes in external $X_{1}, \ldots X_{n}$ factors. 
Therefore, in the general case, the model can be represented as a function:

$\overline{\mathrm{Y}}^{*}=f\left(X_{1}^{*}, \ldots X_{n}^{*}, P_{1}, \ldots P_{m}\right)$

where $P_{1}, \ldots P_{m}$ are internal parameters of the model, which are adequate parameters of the real object of modelling.

Therefore, one of the main issues considered in the development of the model is the question of the accuracy of its compliance with the ratio of factors, properties and parameters of the selected $\bar{Y}$ indicator of the estimated property of the real object of modelling. In other words, how exactly expression (2) corresponds to expression (1). Therewith, it should be borne in mind that combat operations modelling is a rather complex and multifaceted procedure, when the type of equation (2) may be unknown. In this case, the problem is to find this equation. The solution of this problem lies in the plane of experimental theory, which allows, on the basis of selective measurements of the values of $X_{1}^{*}, \ldots X_{n}^{*}$, parameters, and $\overline{\mathrm{Y}}^{*}$ indicator, to find $P_{1}, \ldots P_{m}$ parameterswhen function (2) most accurately reflects real pattern (1). To do this, a comparison of quantitative indicators of modelling results with indicators of the results of actual combat actions (operations) should be performed. Such indicators can be represented by a mathematical expectation of the amount of losses inflicted on the enemy, a mathematical expectation of the losses of friendly troops, and so on.

Each of these indicators depends on a number of random elementary events (the degree of disclosure of the enemy forces disposition, the accuracy of position finding and the degree of damage to its military infrastructure or facilities, the effectiveness of electronic warfare, camouflage, etc.), which depend on probabilistic values accounting procedure of which are approximate in nature. Therefore, the modelling results may differ from the results of actual combat operations. However, the paradigm of modelling combat operations lies in the necessity to develop such a model the quantitative results of which would be most adequate to the quantitative results of real combat operations, as the choice of the most rational plan for their conduct is carried out on a quantitative basis. Based on this, it becomes quite obvious that inadequate quantitative modelling results can result in an inadequate to the real conditions of the situation solution. In addition, here it would be quite appropriate to raise the question: will the commander, who has full responsibility for the decision, trust the results of the modelling, if he is not sure that the quantitative results of the modelling do not contradict the real processes of the combat operations?

The same can be said about the quantitative results of modelling of the combat operations, in which the probability of uncertainty is taken into account through its initial data i.e. the degree of disclosure of the enemy forces disposition, the probability of determining the time of its transition to the offensive employment and so on. In most cases, the values of these probabilities are chosen as their average values, determined on an empirical basis. This is due to the fact that quite often there is no reliable initial data for modelling in the headquarters, for example, data on the probability ratio of defeat of the $i$ target by the $j$ means in $k$ conditions. All this results in an even greater methodological problem i.e. the problem of assessing the reliability of quantitative modelling results. Another no less important point associated with the development of the mathematical apparatus of modelling is to bring it into line with the nature and features of modern armed confrontation. To do this, we introduce the notation: $x(t)$ and $y(t)$ is the strength of troops of the parties at $t \geq 0$ time. Initial conditions (at the initial time) are $x_{0}$ and $y_{0}$, respectively. Therewith, the rate of change in the strength of troops of the parties is determined by three factors: operational losses (proportional to the strength of friendly troops), combat losses (proportional to the strength of enemy troops) and the availability (involvement / non-involvement) of reserves.

Using these notations, the classic combat operations can be described by a system of differential equations of the form:

$x(t)=-a x(t)-b y(t)+u(t)$

$y(t)=-c x(t)-d y(t)+v(t)$

where $a, b, c$ and $d$ are positive constants; and $u(t)$ and $v(t)$ are rates of involvement / non-involvement of reserves.

At the same time, the tactics of guerrilla warfare characteristic of modern conditions can be considered in a system of differential equations such as:

$x(t)=-a x(t)-g y(t)+u(t)$
$y(t)=-d y(t)-h x(t) y(t)+v(t)$

where $g$ and $h$ are positive constants.

The set of simultaneous conduct of classical combat operations and tactics of guerrilla warfare is described by a system of differential equations as follows:

$x(t)=-a x(t)-g x(t) y(t)+u(t)$

$y(t)=-c x(t)-d y(t)+v(t)$ 
These models differ in taking into account the nature and methods of armed confrontation and the dynamics of combat losses growth. Thus, it is assumed that each party destroys the enemy per time unit within the framework of classical combat operations in proportion to its own strength i.e. $b$ and $c$ coefficients are the coefficients of combat effectiveness. These coefficients can be quantified, for example, by the number of shots fired per time unit multiplied by the probability of defeat of the enemy in given conditions. Another type of "guerrilla" operations are combat operations, which depend on the type of fire, losses incurred as a result of its intensity and concentration of troops in the area of combat operations, which is collectively reflected by "mixed" additive component proportional to $x(t)$ and $y(t)$.

The conditions of absence of operational losses and reserves are mainly considered when conducting mixed forms of force groupings use during an armed conflict. In general, it can be noted that the above approach to some extent provides identification of real modelling tasks and considerations of the specifics of modern armed confrontation. The sixth feature of creating models is due to the complexity and variety of combat situations that develop in modern warfare, which require their certain flexibility and versatility to be adequately reflected in the models. To do this, the transition from traditional (sequential) modelling to distributed (parallel) modelling was undertaken.

The main reasons for this transition were:

- Great complexity, volume and variety of modelling tasks, requires not only large time, but also large amounts of memory;

- The need to combine several systems into a single simulation modelling environment (the need to use complexes of models in which the output of one is the entrance to another, and so on);

- Providing the network industry and modern information technologies with the possibility of simultaneous work of official functionaries in the information network with a cluster architecture at a considerable distance from each other.

The construction of distributed modelling systems is based on an architecture that describes the principles of organization of any systems of distributed modelling. Its invariant nature is reflected in the name of HLA (High Level Architecture) i.e. the main international architecture. We will give a brief description of the HLA as a sample of modern technological standards in the field of distributed modelling in relation to the creation of typical architectures, both modelling systems in general, their individual components and problem-oriented applications. Formally, the HLA technology is defined by the following components (Figure 5) [16]:

- Interface specification;

- A template of object models, which specifies the format of information that is of general interest to all participants in the modelling process;

- The basic principles of software development in the HLA environment or according to the standards of this architecture are defined as the ground rules of the HLA;

- Specially designed Run-Time Infrastructure (RTI) to support the HLA, which includes six basic groups for interface management. The RTI performs the functions of a simulator at the level of interactions between federates i.e. a set of services that support coordination of federates and data exchange between them in a single model time;

- Interface specifications that define the interaction with the RTI.

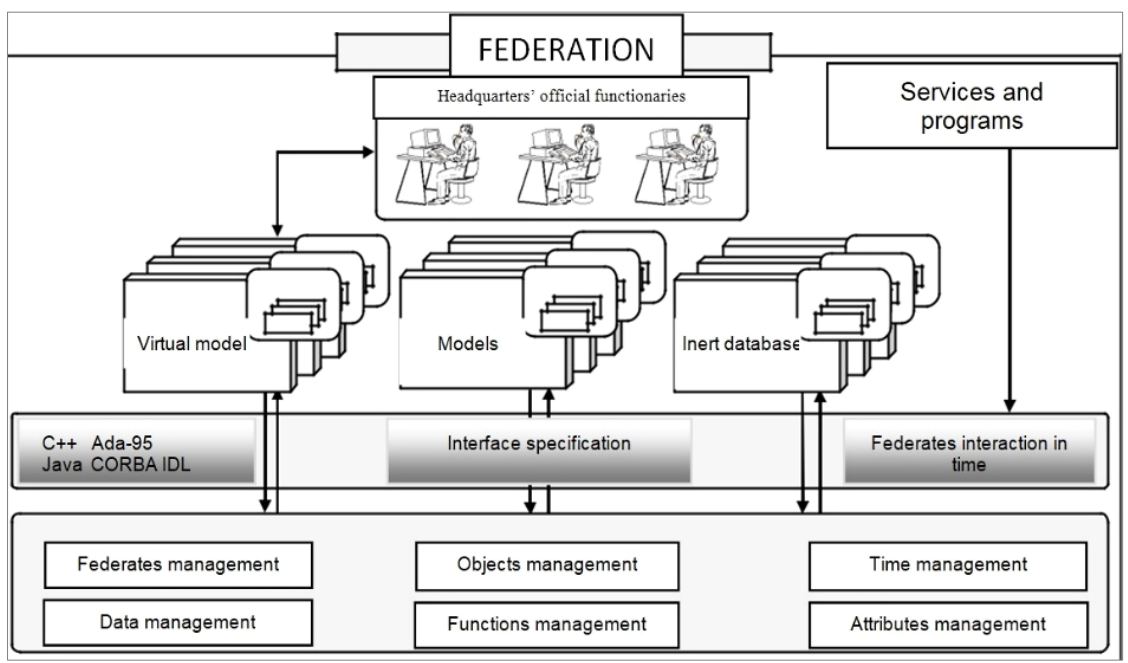

Figure 5. Virtual integrated HLA environment to support the processes of design and implementation of distributed applications. 
Figure 5 shows the structure of support for the development and implementation of distributed applications based on the HLA technology. The federation shown in the figure, which is a distributed application, consists of a large number of functional components located on a distributed architecture. The first type of components are the so-called federates. They can be sequential computer modelling systems, real-time systems, live modelling participants, embedded hardware, programming tool to support various services. Relevant problem-oriented applications are placed on the platform of each of the federates.

It should be noted that the HLA architecture does not impose any restrictions on the implementation of federates and the RTI, but is a set of recommendations on the data formats that federates can exchange and the rules of their interaction in different conditions. Adhering to both, any developer can create both models that can be used in various modelling systems, and their own versions of the RTI infrastructure. Today, simulation modelling is used in order to qualitatively train future commanders, as well as to predict the course of combat operations conduct and its analysis. The simulation modelling provides an opportunity to accomplish the task effectively with lower expenses of material and financial resources, as well as the absence of losses on the part of servicemen and civilians. The commander can clearly solve a task in an artificial combat operation or tactical situation.

The simulation modelling is becoming more widespread when modelling combat operations or actions. It is also possible to create mathematical models, and the battle may involve a large number of weapons, military equipment and servicemen, which causes difficulties in conducting mathematical calculations. Commanders can study the situation as a whole during combat operations or actions, with the required level of detail, using different time intervals by means of simulation models. The created scenario of battle or action will allow you to repeatedly play the scenario and replenish the data needed to create safer combat tactics. An example of simulation modelling of combat operations using the JCATS (Joint Conflict and Tactical Simulation) system is shown in Figure 6.
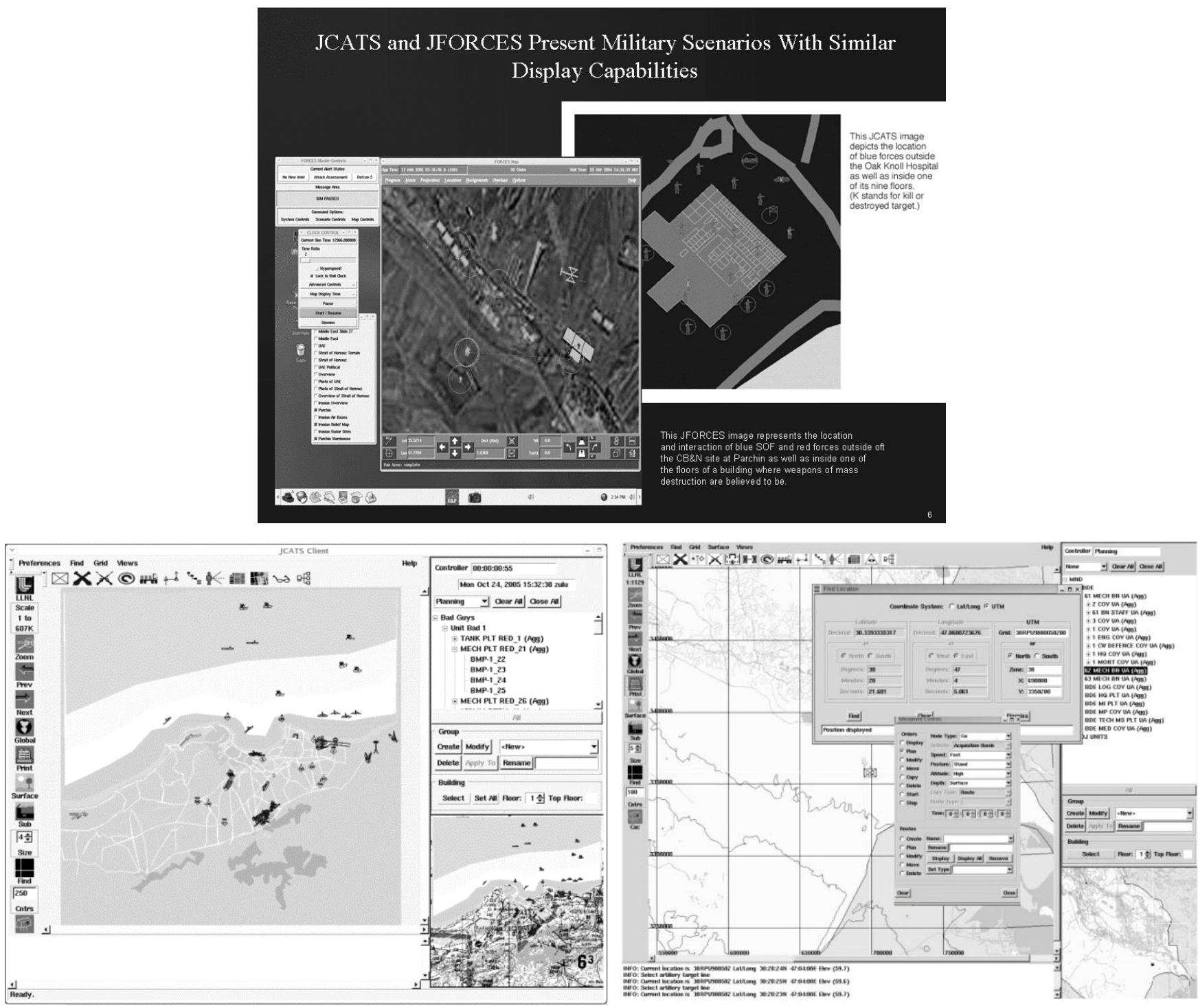

Figure 6. JCATS graphical interface. 
Thus, the command moves from conducting real battles on the battlefield to their multiple use through the possible utilization of modern simulation modelling technologies. At the same time, it is important to raise the level of military and general military training. Not only classic analytical techniques will be used, but also specialized IT tools or constantly developed war games and simulations. With the development and progress of emerging new types of threats and newer forms of fighting, there is a growing need for more and more effective forms of education and improvement of military personnel. Forms and methods of education that emotionally engage, activate to act and have elements of entertainment are therefore not perceived as aggravating. On the contrary, they are more interesting, as they cause a greater and faster absorption of information and Edutainment in the armed forces knowledge. The abovementioned war games and simulations are an outstanding example of edutainment, which serves the multilateral education of the Armed Forces for the needs of current and future threats [20].

It is advisable to form a complex of models for the components of the security and defence sector to ensure the implementation of their tasks. Thus, it is necessary to develop the following list of models on the example of the State Border Guard Service of Ukraine, which is tasked with ensuring the inviolability of the state border and protection of Ukraine's sovereign rights in its adjacent zone and exclusive (maritime) economic zone:

1. Model of actions for border details (surveillance model, patrol model, blocking model).

2. Model of actions for border units during the protection of the state border in everyday conditions.

3. Model of actions for border units during the performance of military tasks.

4. Model of special measures to search for offenders, cessation of armed and non-armed provocations, counteraction to sabotage and reconnaissance groups (illegal armed formations).

5. Model of border operations.

6. Model of combat (fire confrontation).

7. Model of actions at border crossing points.

8. Model of functioning for technical means of border protection.

9. Model of physical and geographical conditions in which border units perform their tasks.

10. Model of service planning.

11. Model of assessing threats, their impact, vulnerability and risk.

12. Comprehensive model of actions for various forces and means to protect the state border.

13. Model of surface picture by means of sea and air protection.

\section{5- Conclusions}

The structure of the complex of simulation modelling of actions of force is formed. The composition of standard models is determined and the sphere of application is outlined, which allows controlling the unit in different situations at the stage of choosing decisions at different levels of management. The simulation model takes into account the capabilities of friendly units and the enemy forces, possible options for the development of the situation (situations). The practical implementation of these approaches, along with the implementation of the principles of costeffectiveness of models, their coordinated development, system compatibility of models for different purposes and large-scale use of proven commercial decisions will create a cluster of combat operations models, which is a real tool for effective decision-making on troops management and allows laying down technical requirements for the development of a modern complex of simulation modelling.

So, as for the prospects. Understanding the situation that the process of model development should not be sustainable, but should be constantly evolving and be adequate to the changes taking place in the nature of modern armed confrontation we have identified the main directions of development of modelling complexes and systems:

- It is proposed to develop the construction of models on the basis of game theory in the field of mixed strategies;

- To provide operational and technical connection of complexes and systems of modelling with operating and perspective command, control, communications, computers and intelligence system;

- To increase the realism of the created conditional combat situation and coordination in time and space of functioning of models of combat operations of various force (troops) grouping;

- To develop a joint system for conducting joint interdepartmental training of tactical and operational-tactical units of the Armed Forces, other military formations and law enforcement agencies. 


\section{6- Declarations}

\section{6-1-Author Contributions}

A.B., V.B., A.Sh., Y.K., V.D., and S.S. contributed to the design and implementation of the research, to the analysis of the results and to the writing of the manuscript. All authors have read and agreed to the published version of the manuscript.

\section{6-2-Data Availability Statement}

The data presented in this study are available on request from the corresponding author.

\section{6-3- Funding}

The authors received no financial support for the research, authorship, and/or publication of this article.

\section{6-4- Conflicts of Interest}

The authors declare that there is no conflict of interests regarding the publication of this manuscript. In addition, the ethical issues, including plagiarism, informed consent, misconduct, data fabrication and/or falsification, double publication and/or submission, and redundancies have been completely observed by the authors.

\section{7- References}

[1] Shannon, R. "Systems Simulation: The Art and Science.” Prentice-Hall, Englewood Cliffs, New Jersey, (June 1, 1975$): 387$.

[2] Bobyliov, V., Zinchenko, Yu., and S. Kononenko. "Principles of Modelling." Modern Information Technologies in the Field of Security and Defence 24, no. 3 (December 29, 2016): 18-23.

[3] Kazmirchuk, R., Ryzhov, Ye., Koroliova, O., and V. Bozhenko. "World Experience and Tendencies of Application of Simulation Modelling Means of Military Operations.” Military and Technical Collection, no. 2 (December 25, 2009): 63-72.

[4] Bakhvalov, V., and V. Hirkh-Yalan. "Simulation Systems for Combat Modelling." Collection of Scientific Works of the Military Institute of the Taras Shevchenko National University of Kyiv, no. 45 (April 17, 2014): 274-278.

[5] Sorokin V., Permiakov A., Masliuk L., and V. Bobylev. "Modelling of Combat Operations of Troops. Mathematical Methods for Substantiating Decisions and Evaluating the Effectiveness of Combat Operations of Troops.” (1995): 218.

[6] Dewar, J., Bankes, S., Hodges, J., Lucas, T., Saunders-Newton, D., and P. Vye. "Credible Uses of the Distributed Interactive Simulation System." RAND, MR607-A, (1996).

[7] Bobylov, V., and R. Timoshenko. "Approach to Data Analysis in the Means of Simulation Modelling of Combat Operations of Troops (Forces)." Modern Information Technologies in the Field of Security and Defence 33, no. 3, (January 17, 2019 ): 5-8.

[8] Derhiliova, O., Roma, O., and O. Pashkov. "Research Planning Using the JCATS Simulation Modelling System." Collection of Scientific Works of the Centre for Military Strategic Studies of Ivan Cherniakhovskyi 3, no. 58, (2016): 65-69.

[9] Shynkaruk, O., and O. Mykhailyshyn. "Some Aspects of the Application of Simulation Modelling in the Preparation of Components of the Security and Defence Sector of Ukraine." Collection of Scientific Works of the National Academy of the State Border Guard Service of Ukraine 80, no. 2, (March 26, 2020): 227-241. doi.10.32453/3.v80i2.201.

[10] Permiakov, O. "Ways of Simulation Modelling Integration in to the Process of Operational and Combat Training of the Armed Forces of Ukraine." Abstracts of the Report at the Department of Staff Informatization (April, 2006): 17-22.

[11] Zaika, L., Lavrinchuk, O., and V. Krainov. "Implementation of the Method of Computer Management Decision Simulation with the Use of Simulation Modelling Means of Combat Operations." Modern Information Technologies in the Field of Security and Defence 39, no. 3, (December 30, 2020): 117-124. doi.10.33099/2311-7249/2020-39-3-117-124.

[12] Kononenko, S., and L. Zaika. "Analysis of the Experience of Using Video Games as a Component of the System of Simulation Modelling of Combat Operations." Collection of Scientific Works of the Centre of Military and Strategic Researches of the National University of Defence of Ukraine, no.1, (March, 2013): 21-24.

[13] Hughes, Wayne P. "Military Modelling for Decision Making." Military Operations Research Society. Third Edition, Alexandria, Virginia (1997).

[14] Fox, Daniel. "Using Exploratory Modelling." New Challenges, New Tools for DefenseDecisionmaking (2003): 258-298. doi:10.7249/MR1576.

[15] Davis, Paul K., Jonathan, Kulick, and Michael, Egner. "Implications of Modern Decision Science for Military DecisionSupport Systems.” (2005). Available online: http://www.rand.org/pubs/monographs/MG360/ (accessed on April, 2021). 
[16] Korolenko, V., Sinyavsky, V., and N. Gochiev. "Modelling Combat Operations as the Main Tool for Making Informed Decisions." Science and Military Security 4, no. 1, (March, 2015): 26-32.

[17] Bratko, A., Hashchuk, V., Suslov, T., Misheniuk, R., Zhuravel, V., and V. Havryliuk. "Assessing the Effectiveness of Tactical Skills Level when Using a Laser Tag Type Two-Way Skirmish Simulator.” BRAIN. Broad Research in Artificial Intelligence and Neuroscience 11, no. 1, (March 17, 2020): 189-203. doi.10.18662/brain/11.1/23.

[18] Furch, Jan, and Quy Hung Nguyen. "Lifetime Test of Tracked Vehicle Torsion Bars Using Monte Carlo Method." Emerging Science Journal 4, no. 5 (October 1, 2020): 376-389. doi:10.28991/esj-2020-01238.

[19] Penchev, Georgi Borisov. "The Use of Constructive and Virtual Simulation Technologies for Skills Training in Military Education." Scientific Journal of the Military University of Land Forces 196, no. 2 (June 26, 2020): 387-394. doi:10.5604/01.3001.0014.2541.

[20] Szczygielska, Agnieszka. "Edutainment in the Armed Forces of the Republic of Poland." Scientific Papers of Silesian University of Technology. Organization and Management Series 2020, no. 145 (2020): 471-483. doi:10.29119/16413466.2020.145.35.

[21] Papachristos, George. "System Dynamics Modelling and Simulation for Sociotechnical Transitions Research." Environmental Innovation and Societal Transitions 31 (June 2019): 248-261. doi:10.1016/j.eist.2018.10.001. 